Case Report

\title{
The Effect of Poetry and Rhythmic Movements Therapy on Reducing Childhood Anxiety of a Child with Myelomeningocele: A Case Report
}

\author{
Masome Amini ${ }^{1}$, Marzieh Pashmdarfard ${ }^{2 *}$ \\ 1. MSc in Clinical Psychology, Zanjan University of Medical Sciences, Zanjan, Iran \\ 2. PhD Student, Department of Occupational Therapy, Iran University of Medical Sciences, Tehran, Iran
}

\begin{tabular}{|c|}
\hline Article Info \\
\hline $\begin{array}{c}\text { Received:2018/11/18; } \\
\text { Accepted:2019/03/17; } \\
\text { Published Online: 2019/03/2 }\end{array}$ \\
\hline DOI: 10.30699/fdisj.2.1.64 \\
\hline How to Cite This Article \\
\hline $\begin{array}{l}\text { Pashmdarfard M. Amini } \\
\text { M. The Effect of Poetry and } \\
\text { Rhythmic Movements Ther- } \\
\text { apy on Reducing Childhood } \\
\text { Anxiety of a Child with My- } \\
\text { elomeningocele: A Case Re- } \\
\text { port Function and Disability } \\
\text { Journal. } 2019 \text { (Winter). Vol:2. } \\
\text { No:1. pages:64-70 }\end{array}$ \\
\hline
\end{tabular}

Use your device to scan and read the article online

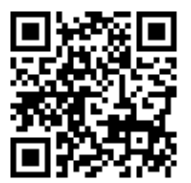

\section{ABSTRACT}

Background and Objectives: Myelomeningocele is a congenital malformation of the central nervous system. Children with this disorder, along with having motor problems, often suffer from behavioral-emotional problems. Anxiety can be annoying, destructive and harmful to the child, due to its impact on all areas of life such as education, interaction with peers, life satisfaction, sense of adequacy and efficiency. Therefore, the present study aimed to investigate the effect of Poetry and Rhythmic Movements Therapy on reducing child anxiety with the diagnosis of Myelomeningocele.

Case Report: The present study is a case study that examines 10 sessions of Poetry and Rhythmic Movements Therapy based on the guidelines for reducing aggression in a 12-year-old child with a diagnosis of myelomeningocele. In this study, the Spence anxiety questionnaire was used. The questionnaire contains 45 phrases (38 score carded terms) that include 6 domains and anxiety domains such as panic and fear of open space, separation anxiety, fear of physical harm, social phobia (phobia), general anxiety and obsessive compulsive disorder - measuring the practice of children aged 8 to 15 years. In this study, the questionnaire was completed before and after the intervention by the caregiver.

Conclusion: Poetry therapy and rhythmic movements can be used as a non-invasive, simple and low-cost treatment and an appropriate way to reduce children's anxiety.

Keywords: Poetry, Rhythmic movements, Myelomeningocele, Anxiety

Copyright (C) 2019, Function and Disability Journal. This is an original open-access article distributed under the terms of the Creative Commons Attribution-noncommercial 4.0 International License which permits copy and redistribution of the material just in noncommercial usages with proper citation.

\section{Introduction}

Spina Bifida (SB) is considered to be the most common disorder in the developmental defect of the nervous system, which is due to the lack of closure of the end of the neural tube during the third to fourth weeks of the juncture (Amini, \& Pashmdarfard, 2017). It seems that a combination of Genetic factors (a history of neural tube defect in previous generations; if following to the birth of a child with this disorder, the probability that a child born with the same disorder is $40 \%$ ), and the environmental factors (consumption Valproic Acid and Carbamazepine in the first trimester of pregnancy, the wrong diet, diabetes, severe fever in early pregnancy, the use of a hot wan bath in early pregnancy, alcohol consumption during pregnancy) can affect this condition (Guilbaud et al., 2019). Generally Spina Bifida is divided into two general types: Spina Bifida occulta and Spina Bifida cystica. Spina Bifida cystica is divided into two types too; the meningocele and myelomeningocele (Ferri, 2017). Spina Bifida occulta, which is also referred to as the hidden Spina Bifida, has no apparent symptoms, but in the type of Spina Bifida cystica the spinal cord and meninges protrude from the neural tube and 
show different motor symptoms (Ferri, 2017). The prevalence of this disorder in the world is between 0.3 and 4.5 per 1,000 live births (Amini, \& Pashmdarfard, 2017). Different statistics in different regions of Iran report the prevalence of this disorder 1.6 per 1,000 live births (Ketabchi, Ghodsi, \& Nejat, 2001). In 90\% of patients, there is also a manifestation of myelomeningocele in the hydrocephalus (Shurtleff, 2012). The physical symptoms of Spina Bifida may include: weakness and lower limb paralysis, orthopedic abnormalities (Club foot, Scoliosis), urinary incontinence and stool, urinary tract infections, and poor kidney function (Juranek, \& Salman, 2010). The presence of multiple physical problems and apparent abnormalities in these children have resulted in behavioral disorders and severe anxiety (Amini, \& Pashmdarfard, 2017). Anxiety is a common, unpleasant and vague feeling of panic with unknown origin that one experiences, including uncertainty, frustration, and physiological excitation (Mosavi, \& Khodabakhshi Koolaee, 2016). Early childhood anxiety disorder is a predictor of psychiatric disorders during adolescence (Mosavi, \& Khodabakhshi Koolaee, 2016). Anxiety disorders are one of the most common forms of pathology in children and adolescents. The disorder has six symptoms: restlessness, extreme fatigue, difficulty in concentration, irritability, muscle tension and sleep disorder (Khodabakhshi koolaee, Sabzian, \& Falsafi nejad, 2015). In recent years, researchers have been struggling to introduce effective interventions for anxiety disorders. Although there are several interventions for treating anxiety, but the new methods such as art therapy (poetry, painting therapy, theater therapy, music therapy) has become very important in recent decades (Mosavi, \& Khodabakhshi Koolaee, 2016). Many studies showed the positive effect of poetry therapy on a range of physical and psychological disorders, such as reducing anxiety in cancer patients, reducing pain, addiction and other mental disorders (Mosavi, \& Khodabakhshi Koolaee, 2016; Khodabakhshi koolaee, Sabzian, \& Falsafi nejad, 2015). Poetry therapy was officially recognized in 1969, until then, little research was done on its different applications and therapeutic efficacy. The therapeutic goals expected of therapeutic poetry are: to empower the feeler, promote self-expression and spread group discussion. Of course, the choice of proper lyrics and time should also be taken into consideration. Poetry therapy, like Freud's psychotherapy, leads to emotional liberation, which is rooted in depression and anxiety and individual stress. (Khodabakhshi koolaee, Sabzian, \& Falsafi nejad, 2015). In addition to the curriculum, rhythmic movements' therapies are also known as one of the effective methods for reducing anxiety disorders (Khodabakhshi koolaee, Sabzian, \& Falsafi nejad, 2015). Since rhythmic movements' therapy, like poetry, provide a way to express feelings, particularly for children who are verbally insufficient to express their feelings. Their movement symbols are a reflection of their inner feelings, in other words, rhythmic movements' therapy can play the role of their language (Mohammadian et al., 2011). Therefore, this study was designed to assess the effect of poetry therapy and rhythmic movements' therapy on reducing anxiety of a child with myelomeningocele.

\section{Case Report}

this study is about the effect of Poetry therapy and rhythmic movements' therapy on reducing anxiety of a 12 years old boy (he was born in 2004) with myelomeningocele and IQ of 104\% in 2018. The child has entered third elementary school; his parents have got divorced and the child is now not under the care of any of his parents being cared in the children care center. In this study, an anxiety scale (The Spence Children Anxiety Scale (SCAS): child report and caregiver report) was used to assess the anxiety of the child.

\section{The Spence Children Anxiety Scale (SCAS)}

This scale was developed by Spence in Australia in 1997 according to the DSM-IV diagnostic classification (Spence, \& Barret, 2003). The Spence Children Anxiety Scale consists of 45 phrases, 38 phrases are scored and six phrases which are positive are not scored and computed. Spence Children Anxiety Scale also has an open question that the child will respond in an explanatory way and can be provided for 8 to 15 years old children. The Spence Anxiety Scale has 6 sub-scales that are as follows: 
1. Panic and fear of open space: This scale is evaluated in questions 13-21-28-30-32-34-36-37-39.

2. Separation anxiety: This scale is evaluated in questions 5-8- 12- 15- 16-44.

3. Fear of physical damage: This scale is evaluated in questions 2-18-23-25-33.

4. Social phobia (phobia): This scale is evaluated in questions 6-7-9-10-29-35.

5. Obsessive-Compulsive: This scale is evaluated in questions 14-19-27-40-41-42.

6. General anxiety: This scale is evaluated in questions 1-3- 4 20-22-24. The scoring of this scale is based on a 4-point Likert scale, never (0), sometimes (1), often (2), and always (3). The test retest reliability of the original version of this scale was reported by Spence et al. in 1998 for general anxiety $(\mathrm{ICC}=0.92)$
(10). The internal consistency of this scale in Iran was reported by Mousavi et al in 2007 with Cronbach's alpha between 0.62 and $0.89(0.62<\alpha<0.89)$, and the 6 sub-scales were confirmed by confirmatory factor analysis (Mousavi et al., 2007).

\section{Poetry therapy and rhythmic movements' therapy}

Due to certain conditions (myelomeningocele) of this boy the purposes of rhythmic movements' therapy in this study, were gross and fine motor movements of the hands, fingers, head, and trunk, lower limb, lying and sitting. In this study, the poetry therapy and rhythmic movement therapy were conducted in 10 sessions with specific topics (45 to 60 minutes each session) (9) In this study, poetry and rhythmic movements therapy were performed in 45 days ( 2 sessions per week and 45 to 60 minutes in each session), which is described in detail in Table 1.

Table 1. Poetry and rhythmic movement therapy

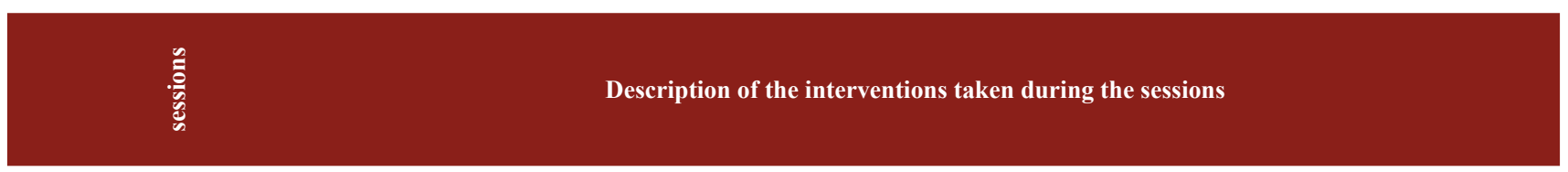

Familiarity with the therapist and the rules of poetry and rhythmic movement therapy, the full description of the ther-

1

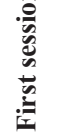
apist to the child in relation to poetry and rhythmic movements therapy, two-way treaty (between the child and the therapist) to observe the rules, complete the Spence children's anxiety Scale, by the child and the child caregiver (the boss of caregiver center).

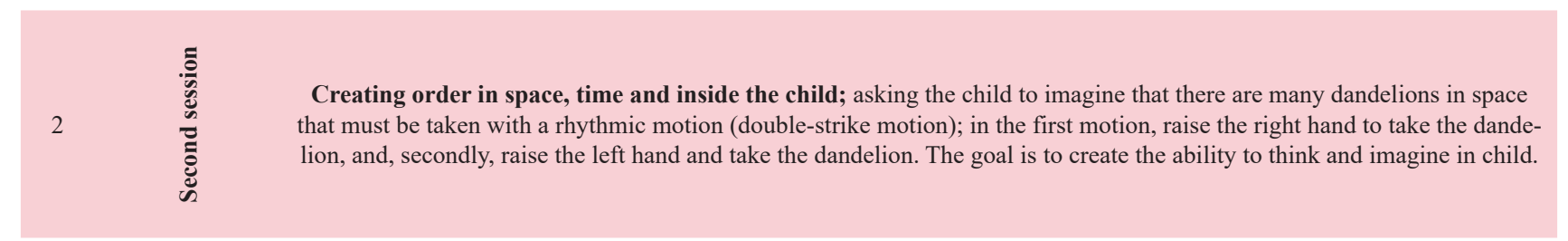

$3 \quad$ 葋

Creating and enhancing the sense of participation; Child's poetry therapy was done by the psychologist and for performing rhythmic movements in harmony with the content of the poem for the purpose of mental imagery and cognitive skills in the child the occupational therapist helped too.

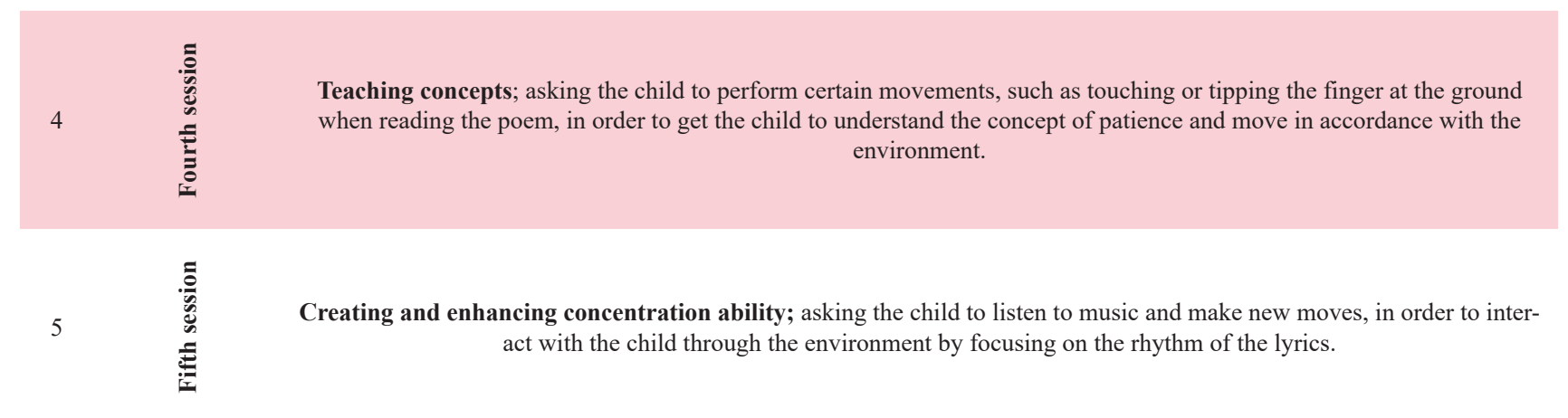




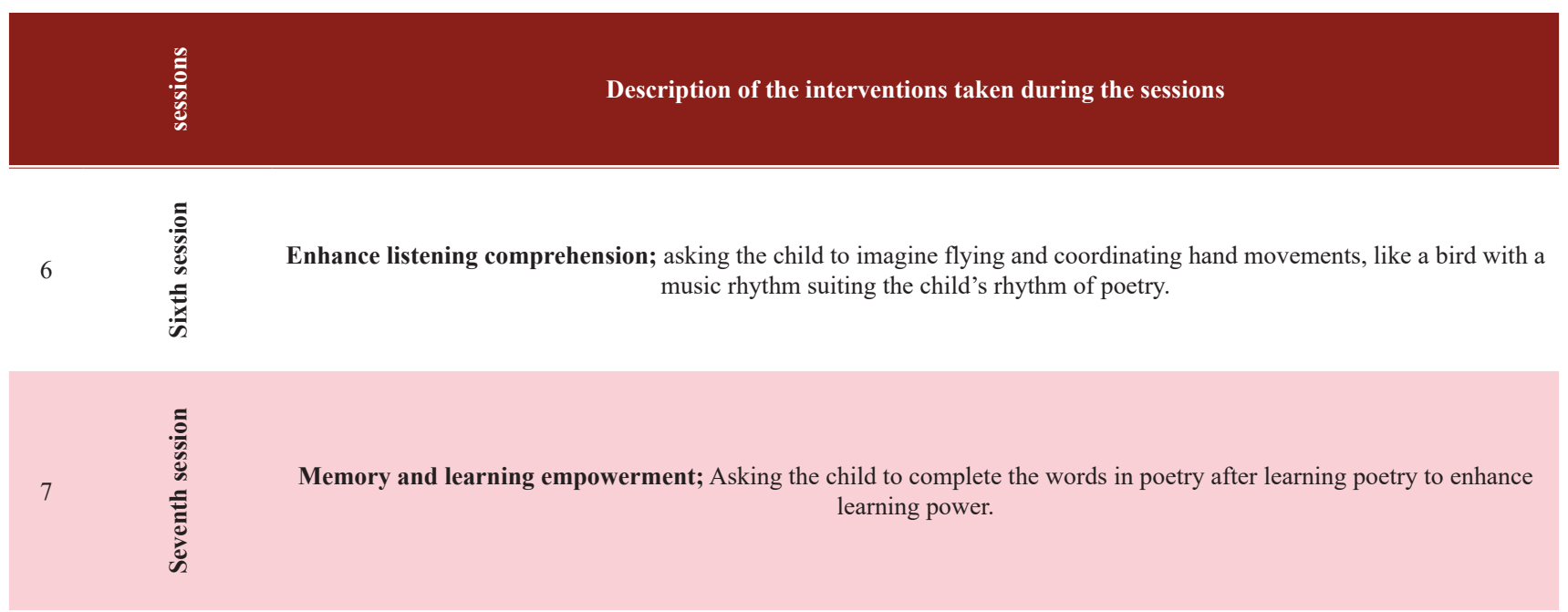

$8 \quad \frac{0}{0}$

Relaxing; asking the child to lie down on the ground; relaxing the hands; and, at the same time, breathing deeply while listening to music, in order to reduce the child's anxiety.

$9 \quad$ 产

Increasing creativity; asking the child to perform movements with poetry to enhance the child's adaptation to environmental changes.

$10 \quad \frac{0}{0}$

Pretending; reading poems about jobs and asking the child to make moves appropriate to the owner of the job in order to strengthen the imagination of the child.

\section{Results}

This study was performed to assess the effect of poetry and rhythmic movements' therapy on reducing child anxiety with myelomeningocele. Poetry and rhythmic movements' therapy were conducted in accordance with the specific instructions during 10 sessions. In each session a specific topic was presented individually to the child. After ten sessions, the results showed the effectiveness of Poetry and rhythmic movements' therapy for reducing the anxiety of the child. Interventions have been able to reduce the fear of open space, separation anxiety, fear of physical damage, social phobia, and general child anxiety, but the results didn't show the effectiveness of Poetry and rhythmic movements' therapy on reducing the obsessive-compulsive anxiety. Regarding these results, Poetry and rhythmic movements' therapy have been effective in reducing the anxiety of the child with myelomeningocele (Table 2).

Table 2. Result of poetry and rhythmic movement therapy based on SCAS

\begin{tabular}{|ccc|}
\hline & Before interventions & After interventions \\
\hline Panic and fear of open space & 16 & 14 \\
\hline Separation anxiety & 12 & 11 \\
\hline Fear of physical damage & 6 & 4 \\
\hline Social phobia (phobia) & 5 & 3 \\
\hline Obsessive-Compulsive & 5 & 6 \\
\hline General anxiety & 3 & 2 \\
\hline
\end{tabular}




\section{Discussion}

This case study, showed the effect of poetry and rhythmic movements' therapy on reducing child anxiety with myelomeningocele. Several studies have been done on the effect of poetry and rhythmic movement's therapy on children anxiety (Khodabakhshi koolaee, Sabzian, \& Falsafi nejad, 2015; Mosavi, \& Khodabakhshi Koolaee, 2016), in a study conducted among preschoolers, by Khodabakhshi et al., poetry and rhythmic movements therapy was proposed as a low cost and efficient intervention method in reducing the aggression and anxiety of children (Khodabakhshi koolaee, Sabzian, \& Falsafi nejad, 2015). Mohammadian et al., also considered poetry therapy to reduce anxiety, depression and aggression of children (2011). Pouyamanesh and Faryabi also showed that poetry and rhythmic movements' therapy reduce the aggression in mentally retarded children and children with learning disabilities (2015). The point to consider in this study was that these interventions have been performed on a child with myelomeningocele. Since the child was not under the care of any of the parents and was kept at a care center for children with physical disabilities, the child therapist's hypothesis was that the child's anxiety would be due to his difficult circumstances; In this regard proper steps were taken to help with the child's anxiety. The results of the study showed that poetry and rhythmic movement's therapy can be effective in reducing the anxiety of this child. In a study by Amini and Pashmdarfard to investigate the effect of painting therapy on reducing child aggression with myelomeningocele, it has been shown that painting therapy is effective in reducing aggression (Amini \& Pashmdarfard, 2017). Considering this study, as well as similar studies, one can conclude that providing services such as poetry therapy, rhythmic movements' therapy, painting therapy can be effective in reducing the distressing psychological symptoms of children, especially children with special needs.

\section{Conclusion}

Poetry and rhythmic movements therapy was an effective treatment to reduce the anxiety of children with myelomeningocele. However, since this study was performed only on a person, in order to increase its generalizability and widespread use, more studies are needed with more sample size. But since these therapies, including non-invasive, simple and costeffective therapies can be suggested along with other therapeutic and rehabilitation methods for these children, in addition to the sensory-motor disorders of these children, we also have a step toward eliminating behavioral disorders in these children.

\section{Acknowledgement}

This research did not receive any specific grant from funding agencies in the public, commercial, or not-for-profit sectors. The authors appreciate the child and Nasim care center's Personnel especially Mrs. Mohammadi who was the Nasim care center's director

\section{Conflict of Interest Statement}

Authors declared no conflict of interest.

\section{References}

Amini, M., Pashmdarfard, M. (2017). Effect of Painting Therapy on Reducing the Aggression of a Child with Myelomeningocele: A Case Study. The Scientific Journal of Rehabilitation Medicine, 6(4), 278-283.

Ferri, F. Ferri's Clinical Advisor 2017: 5 Books in 1. 1st Edition, Elsevier Health Sciences. p. 1188.e2.

Guilbaud, L., Roux, N., Friszer, S., Dhombres, F., Vialle, R., Shah, Z., ... \& Jouannic, J. M. (2019). Two-port fetoscopic repair of myelomeningocele in fetal lambs. Fetal diagnosis and therapy, 45(1), 36-41.

Juranek, J., \& Salman, MS. (2010) Anomalous development of brain structure and function in spina bifida myelomeningocele. Dev Disabil Res Rev, 16(1), 23-30.

Ketabchi, S. E., Ghodsi, S. M., \& Nejat, F. (2001). Incidence of gross nervous system anomalies in newborns at two obstetric centers in Tehran. J of medical council of IR Iran, 18(4), 277-281.

Khodabakhshi koolaee, A., Sabzian, M., \& Falsafi nejad, M. R. (2015), Impact of poetry therapy and movement/ dance therapy in decreasing aggression and anxiety among preschool children. JPEN, 1 (4), 11-21.

Mohammadian, Y., Shahidi, S., Mahaki, B., Mohammadi, 
69. The Effect of Poetry and Rhythmic Movements Therapy...

A. Z., Baghban, A. A., \& Zayeri, F. (2011). Evaluating the use of poetry to reduce signs of depression, anxiety and stress in Iranian female students. The arts in psychotherapy, 38(1), 59-63.

Mosavi, H. S., \& Koolaee, A. K. (2016). Effectiveness of Client-centered Play Therapy on Fear and Anxiety in Preschool Children. Community Health (Salāmat-i ijtimāī), 3(4), 261-269.

Mousavi, R., Moradi, A. R., Farzad, V., \& Mahdavi, S. (2007). Psychometric properties of the Spence children's anxiety scale with an Iranian sample. Int J of Psycholy, 1(1), 17-26.
Poyamanesh J, Faryabi Z. (2015). Compare the Effectiveness of Rhythm Games on Decreasing Aggression Children with Mild Mental Retardation and Children with Learning Disorders with Normal Children. Management and Administrative Sciences Review. 4(1), 189- 197.

Shurtleff, D. (2012). Fetal endoscopic myelomeningocele repair. Developmental Medicine \& Child Neurology, 54(1), 4-5.

Spence, S. H., Barrett, P. M., \& Turner, C. M. (2003). Psychometric properties of the Spence Children's Anxiety Scale with young adolescents. Journal of anxiety disorders, 17(6), 605-625. 


$$
\text { كزارش موردى }
$$

\title{
تاثير شعر درمانى و حركات ريتميك بر كاهش اضطراب كودكى با تشخيص ميلومننغَوسل: كزارش موردى
}

\author{
معصومه امينى'، مرضيه קشممدارفرد؟"
}

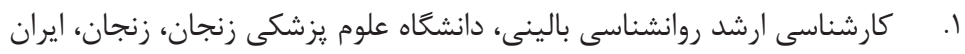

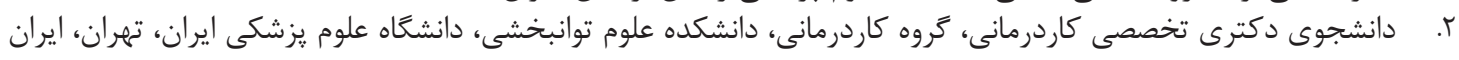

\begin{tabular}{|c|c|}
\hline קكيده & اطلاعات مقاله \\
\hline 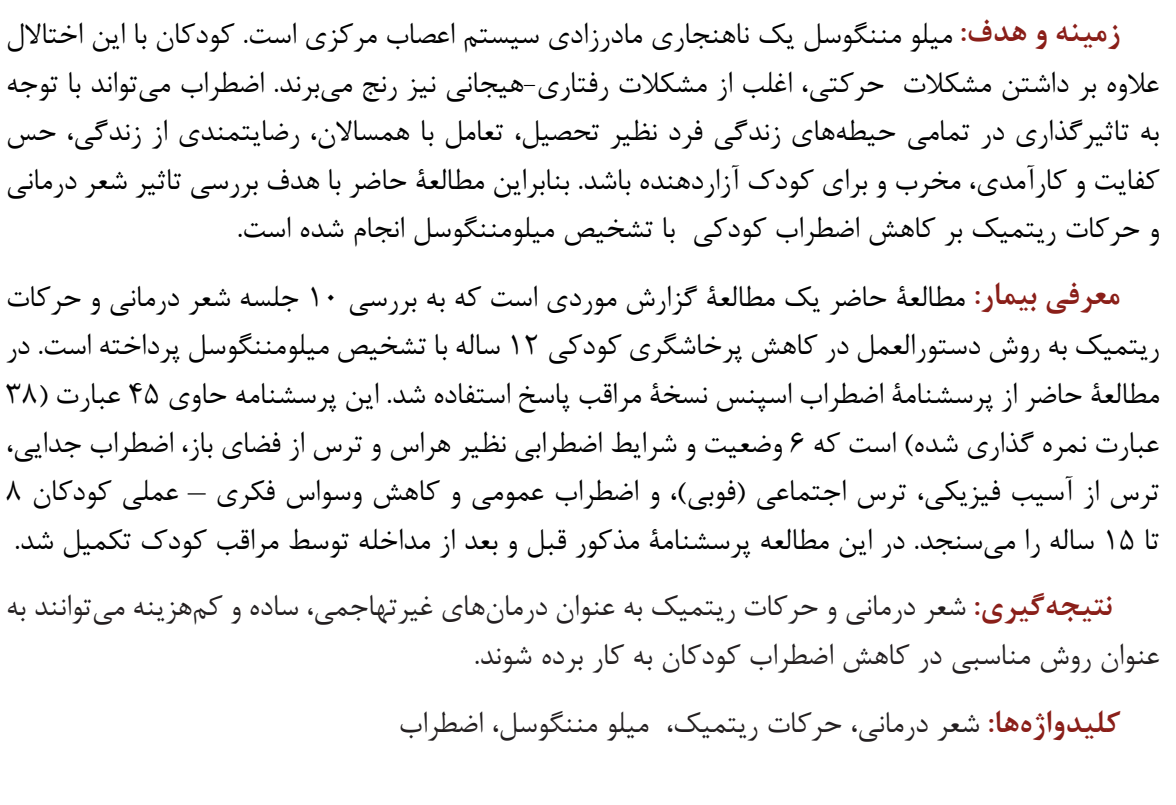 & 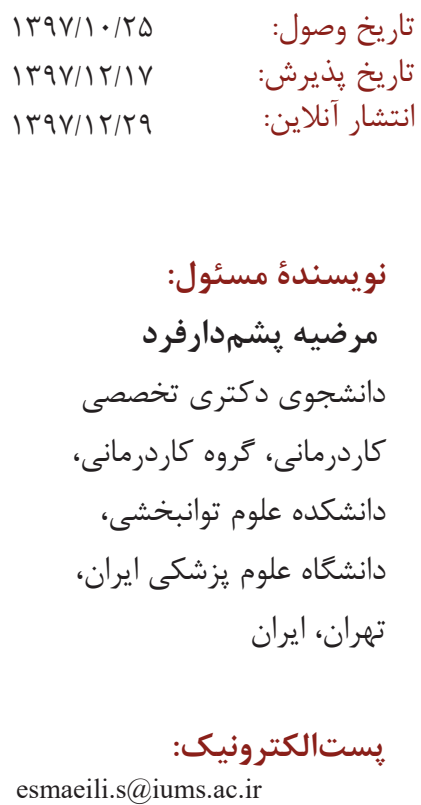 \\
\hline
\end{tabular}

